\title{
IN-HOME TELEREHABILITATION FOR OLDER PERSONS WITH CHRONIC OBSTRUCTIVE PULMONARY DISEASE: A PILOT STUDY
}

\author{
MiCHEL TOUSIGNANT, PT, PHD ${ }^{1,2}$, NiCOLE MARQUIS, PT, MSC ${ }^{2}$, \\ CATHERINe PAGÉ, MSC ${ }^{1}$, NinetTe IMUKUZE, MPT², ANNiE MÉtivier, MPT², \\ VALÉRIE ST-ONGE MPT22, ANNIE TREMBLAY, MPT2 \\ ${ }^{1}$ ReSEARCH CENTRE ON AGING, SHERbroOKE GERIATRIC UNIVERSITY INSTITUTE, FACULTY Of MEDICINE \\ and Health Sciences, Université de Sherbrooke, Sherbrooke, Québec, Canada \\ 2 SCHOOL OF REHABILITATION, FACULTY OF MEDICINE AND HEALTH SCIENCES, \\ Université de Sherbrooke, SHerbrooke, Québec, CANADA
}

\section{ABSTRACT}

The purpose of this pilot study was to investigate the efficacy of in-home telerehabilitation for people with Chronic Obstructive Pulmonary Disease (COPD). Three community-living elders with COPD were recruited in a rehabilitation outpatient group and by direct referrals from pneumologists with outpatients who have COPD. A pre/post-test design without a control group was used for this pilot study. Telerehabilitation sessions (15 sessions) were conducted by two trained physiotherapists from a service center to the patient's home. Locomotor function (walking performance) and quality of life were measured in person prior to and at the end of the treatment by an independent assessor. Clinical outcomes improved for all subjects except for locomotor function in the first participant. In-home telerehabilitation for people with COPD is a realistic alternative to dispense rehabilitation services for patients requiring physical therapy followup.

Keywords: Telerehabilitation, Chronic Obstructive Pulmonary Disease

\section{INTRODUCTION}

Chronic Obstructive Pulmonary Disease (COPD) is a major health problem. In 2005, this pulmonary disease was the fourth cause of mortality in Canada (Bourbeau et al., 2005). It is also estimated that the mortality rate from COPD will continue to grow until it becomes the third mortality cause by 2013 (Bourbeau et al., 2005). This pathology is characterized by a progressive bronchial obstruction associated with airway inflammatory process (O’Donnell et al., 2003; Pauwels et al., 2001). It causes symptoms such as shortness of breath, cough and abundant production of mucus (Ferguson \& Cherniack, 1993), which result in intolerance for effort. It has a major impact on people's daily lives and ability to perform their activities, with disastrous consequences on their quality of life (Gosker, Wouters, van der Vusse \& Schols, 2000; O'Donnell et al., 2003).

Pulmonary rehabilitation helps to prevent a downward spiral of deconditioning in patients with COPD, leading to exacerbations, deterioration in quality of life and disability (Pepin, Saey, Laviolette \& Maltais, 2007; Puhan, Scharplatz, Troosters \& Steurer, 2005; Spruit et al., 2003). Pulmonary rehabilitation programs typically comprise exercise training, patient education and sometimes psychological support. In addition, pulmonary rehabilitation decreases health care utilization (Bourbeau et al., 2003). Its efficacy has been documented in controlled clinical trials (Maltais et al., 2008; Ries, Kaplan, Limberg \& Prewitt, 1995) and meta-analyses (Lacasse et al., 2002; Lacasse, Martin, Lasserson \& Goldstein, 2007; Lacasse et al., 1996) to reduce dyspnea, increase tolerance for exercise and improve health-related quality of life as well as functional status. Unfortunately, pulmonary rehabilitation is greatly underutilized (Brooks et al., 2007). In 2005, only an estimated $1 \%$ to $2 \%$ of the Canadian population with COPD had access to pulmonary rehabilitation services at hospital outpatient clinics or at home (Brooks et al., 2007). This clearly shows that these services are not able to serve the needs of patients with COPD (Brooks et al., 2007). In this context, the health care system must develop new strategies to increase access to pulmonary rehabilitation services.

As a new way to deliver health care services, telerehabilitation, which is defined as a telehealth application using telecommunication technologies to 
dispense rehabilitation services, is a new approach in the rehabilitation domain that allows patients to get treatment at home via the Internet while the clinician is at a clinic (Ricker et al., 2002). This innovative way to deliver rehabilitation services could be a good way to increase accessibility.

Some telerehabilitation applications have addressed language and speech disorders (Duffy, Werven \& Aronson, 1997; Hill et al., 2006; Theodoros, Russell, Hill, Cahill \& Clark, 2003), mental health (Ball \& McLaren, 1997) and physical health such as wounds (Halstead et al., 2003; Rintala et al., 2004; Vesmarovich, Walker, Hauber, Temkin \& Burns, 1999), orthopedic (Aarnio, Lamminen, Lepistö \& Alho, 1999; Lemaire, Boudrias \& Greene, 2001; Ohinmaa, Vuolio, Haukipuro \& Winblad, 2002; Tousignant, Boissy, Corriveau \& Moffet, 2006; Tousignant et al., 2011) and neurological conditions (Savard, Borstad, Tkachuck, Lauderdale \& Conroy, 2003). These studies demonstrated the feasibility of teletreatment. To our knowledge, there is no study on telerehabilitation with patients with COPD. In this context, the main purpose of the study was to explore the feasibility of an in-home telerehabilitation program for people with COPD.

\section{METHODS}

\section{DESIGN}

The design was a pre-experimental pilot study with pre/post-tests and no control group. Participants were assessed before the program (T1), and again after the eight-week program (T2). Both assessments were performed by an independent research assistant under the supervision of medical staff.

\section{SAMPLE}

People with COPD were recruited in a rehabilitation outpatient group and by direct referrals from pneumologists with outpatients who have COPD. For the rehabilitation outpatient group, the first meeting provided information about the purpose of the study and briefly described the participants' role. Patients interested in participating were asked to give their names to the research assistant. On the other hand, pneumologists obtained verbal consent from their patients to be contacted by the research assistant. In both recruitment scenarios, the patient received a call from a member of the research team who gave more information about the study. If the patient was still interested in participating, he/ she was invited to sign the consent form.

Inclusion criteria were: 1) forced expiratory volume in one second (FEV1) between 30 and 50\% (as indicated in the medical record); 2) no contraindication for physical exercise; 3) sufficient verbal and written understanding of the instructions to participate in a remote treatment and fill out questionnaires; and 4) access to a high speed Internet connection. The only criterion for exclusion was oxygen dependency.

\section{TECHNOLOGICAL INFRASTRUCTURE FOR TELEREHABILITATION SERVICES}

Based on experience from two previous studies (Boissy, Tousignant \& Corriveau, 2005; Tousignant, Boissy, Corriveau \& Moffet, 2006), a telerehabilitation platform was developed and refined. The platform included various components in order to provide a user-friendly experience for both the clinician and the patient at home. While they were similar in many ways, two different systems were used to provide telerehabilitation services: an "in-home" system and a clinician system. The telerehabilitation platform and software interface for both systems are illustrated in Figure 1.

Figure 1. Telerehabilitation systems 
Components of both systems: A) videoconferencing system, B) LCD screen, C) router and modem connecting to the Internet, D) sensors and external devices, E) clinician computer and screen display.

The core of these systems was the videoconferencing system (Tandberg 550 MXP), which used a h.264 video codec and integrated a pan-tilt-zoom (PTZ) wide angle camera and an omnidirectional microphone. The system was mounted over a 25.5 inch touchscreen computer. The computer was used to display the video received from the other end, but was also used as a sensor display for the patient. Audio was played using external speakers placed on both sides of the screen. Video and audio data were encrypted and transmitted over a high-speed Internet connection, allowing communication using a maximum bandwidth of $512 \mathrm{kbps}$ for both upload and download. The system was also resilient to packet loss and ensured that audio and video were correctly synchronized. The inhome system included a wireless oxymeter sensor. This sensor provided additional information in real time to the clinician, such as oxygen saturation level and heart rate. The bandwidth will vary according to the number and type of sensors included in the setup but is currently very low since data is transmitted at $1 \mathrm{~Hz}$.

The computer installed at home served as a base station for the sensor network and was wirelessly connected to the router. Sensors illustrated in the picture include: inertial measurement units, respiratory belts, pulse oxymeters and instrumented soles.

On the clinician's side, a similar system was used. A software interface (TeRA) running on the clinician's computer provided user-friendly control and monitoring of videoconferencing sessions, control of the cameras, built-in clinical tests, photo and video recording and external sensors and devices support (Hamel, Fontaine $\&$ Boissy, 2008). The platform was developed to ensure that interactions between clinicians and clients during the telerehabilitation sessions were not impeded by technology but facilitated with user-friendly interfaces. A special effort was made to provide a mouse-based interface to intuitively control, from a unique screen through point-and-click or area zoom, PTZ camera functions at both sites.

\section{OUTCOME MEASURES}

Function was measured using aerobic capacity assessed by the standardized six- minute walk test (6MWD) (Rasekaba, Lee, Naughton, Williams \& Holland, 2009). This test is frequently used to evaluate the functional capacity of patients with COPD (Celli et al., 2004; Rasekaba et al., 2009). During the test, patient walks around and around on a regular plane surface for six minutes, trying to cross biggest distance; encouragement is given every minute. Heart frequency and oxyhemoglobin saturation were measured before and after the test. The 6MWD test has demonstrated high validity and reliability in assessing changes in functional capacity following pulmonary rehabilitation in patients with chronic obstructive lung disease (Rejbi et al., 2010).

Quality of life was evaluated with the French version of the Chronic Respiratory Questionnaire (CRQ). The questionnaire has 20 items divided into 4 domains: 1) dyspnea, 2) fatigue, 3) emotional function, and 4) mastery. Each item is rated on a numeric scale from one to seven. A higher score is associated with good quality of life. The $\mathrm{CRQ}$ presents very good validity and reliability (Bourbeau, Maltais, Rouleau \& Guímont, 2004). The minimum significant difference is a half point on a 7-point scale (Bourbeau et al., 2004).

Adherence to the program was evaluated by a penand-paper journal. Each participant was asked to record in the journal each time he/she did the exercise program, including the time spent on the stationary bike, level of dyspnea, $\mathrm{SaO} 2$ (with a probe) and number of repetitions of each strengthening exercise.

\section{TELETREATMENT: PHYSIOTHERAPY PROGRAM}

The treatment was a home-based pulmonary telerehabilitation program. The main purpose of the program was to improve muscle and aerobic capacity. The program was divided into four parts: 1) warm-up and stretching, 2) strengthening, 3) cardiorespiratory endurance, and 4) cool-down. The program was based on the institution home pulmonary rehabilitation program and the "Living well with COPD program" developed by the Montreal Chest Institute (Bourbeau \& Nault, 2009).

The cardiorespiratory training was given on a stationary bike and lasted between 10 and 45 minutes depending on the individual's physical condition. After each session, some physiological responses to exercise were measured to be sure that the participant was fine: 1) dyspnea (modified Borg scale) (Borg, 1982), 2) heart frequency, and 3) $\mathrm{SaO} 2$ (had to be $88 \%$ or over) obtained from the probe.

The program was given over an eight-week period. The number of teletreatments decreased gradually to be replaced by unsupervised treatments in order to give and develop the patients' motivation to do the exercises by themselves in the future. The schedule followed was the same for all participants: 1) weeks 1 and 2: three teletreatments, none without supervision; 2) weeks 3 , 4 and 5: two teletreatments, one without supervision; 3) weeks 6, 7 and 8: one teletreatment, two without supervision. 


\section{RESULTS}

Descriptive statistics of the sample

Three participants were enrolled in this pilot study. The first participant was a man (68 years old), the second was a woman (60 years old) and the last was a man (45 years old). Their FEV1 scores were $42 \%, 55 \%$ and $50 \%$, respectively.

\section{Locomotor function (walking performance)}

In the 6MWD, two of the three participants showed significant improvement (more than 54 meters) while no change was observed for the other. Figure 3 presents the results of the 6MWD for the three participants.
Figure 3. 6-minute walk test

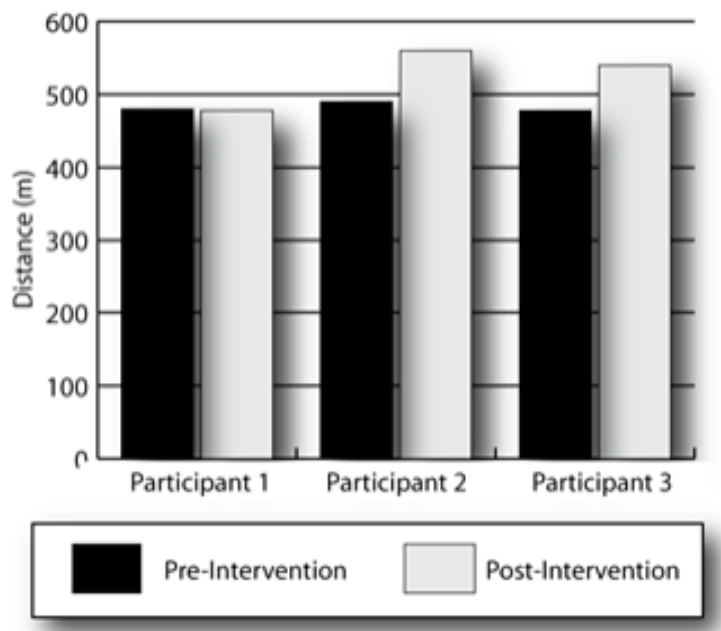

\section{QUALITY OF LIFE}

For all the dimensions of quality of life (dyspnea, fatigue, emotions, mastery), all participants showed a trend towards better quality of life. Results of the MCQ questionnaire are presented in Figure 4.

Figure 4. Chronic Respiratory Questionnaire scores

\section{(A)}

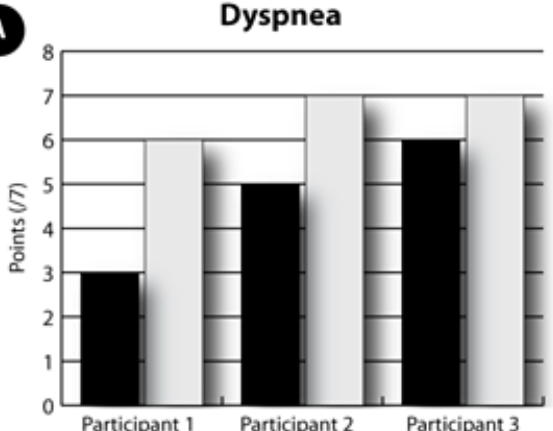

(C)

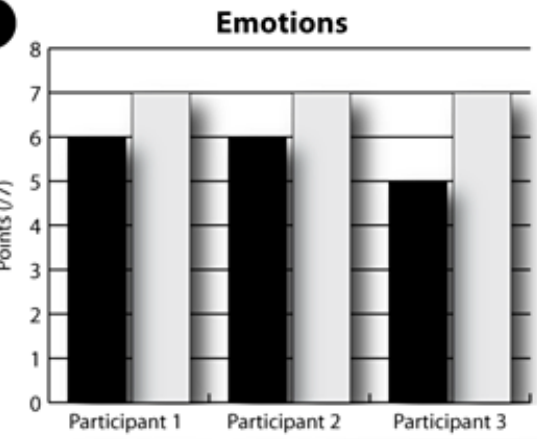

B

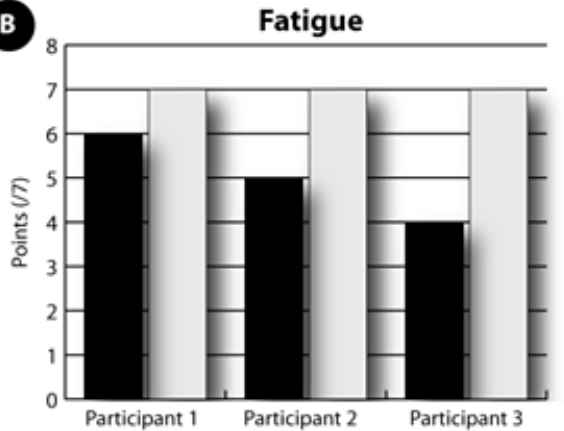

D
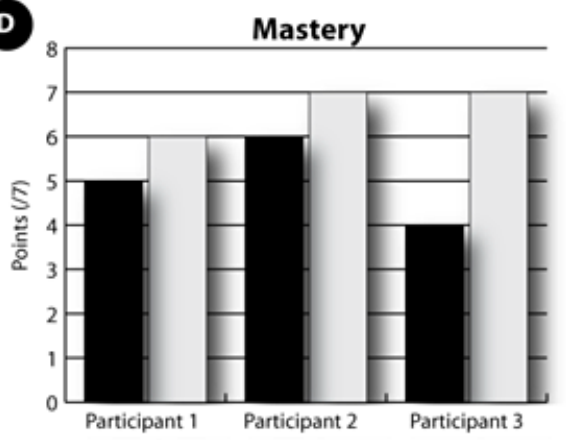

Pre-Intervention Post-Intervention 


\section{DISCUSSION}

The objective of this pilot study was to investigate the feasibility of delivering a pulmonary exercise program by telerehabilitation between the patient's home and a clinic for patients with COPD. To our knowledge, this is the first study to illustrate the feasibility of carrying out a complete telerehabilitation program for this population. Our study showed clinically relevant positive changes in locomotor function (walking performance) and quality of life after the intervention.

For the first participant no notable improvement was obtained in locomotor function. This result may be partly because the participant had an exacerbation during the last week of the program. Although he had a pulmonary complication just before the second evaluation, there was no clinically significant decrease in the 6MWD. However, this participant showed a significant clinical improvement in the four domains evaluated for quality of life (dyspnea, fatigue, emotional function and mastery). The second and third participants both showed a significant clinical improvement in locomotor function and in the four domains evaluated for quality of life. These results indicate the clinical relevance of teletreatment with people affected by COPD.

Regarding study limitations, selection bias was probably an issue. Patients who agreed to participate were probably more motivated and willing to explore new types of therapy. To ensure the participants' safety, the level of dyspnea was assessed at different time points during treatment with the modified Borg Scale.

To diminish information bias, the independent assessor evaluated the participants with standardized instruments.

From a technical standpoint, occasional disconnection problems occurred during the program. However, they did not affect the overall clinical experience, even if heart frequency and $\mathrm{SaO} 2$ could not be assessed during the program.

Even with the small sample size $(n=3)$ of this study, it was possible to determine the feasibility of in-home pulmonary rehabilitation teletreatment.

\section{CONCLUSION}

Teletreatment seems to be a practical way, both clinically and technically, to dispense rehabilitation services for patients with COPD. Further research is needed with a more powerful design (e.g. randomized controlled trial) to measure the efficacy of this novel way of delivering a pulmonary rehabilitation program through teletreatment. 


\section{REFERENCES}

1. Aarnio, P., Lamminen, H., Lepistö, J., \& Alho, A. (1999). A prospective study of teleconferencing for orthopaedic consultations. Journal of Telemedicine and Telecare, 5(1), 62-66.

2. Ball, C., \& McLaren, P. (1997). The tele-assessment of cognitive state: a review. Journal of Telemedicine and Telecare, 3(3), 126-131.

3. Boissy, P., Tousignant, M., \& Corriveau, H. (2005). Téléréadaptation à domicile pour le suivi des personnes ayant subi une arthroplastie du genou: Étude pilote. Disability and Rehabilitation: Assistive technology, 1, 209-216

4. Borg, G. (1982). Psychological bases of perceived exertion. Archives of Internal Medicine, 14(5), 377-381.

5. Bourbeau, J., Bryanton, V., Lapointe, L., Shaw, M.-P., Mac Farlane, A., Abog-Morrant, K., et al. (2005). Chronic Obstructive Pulmonary Disease (COPD) - A national report card. The Lung Association and Canadian Thoracic Society. p. 1-38.

6. Bourbeau, J., Julien, M., Maltais, F., Rouleau, M., Beaupré, A., Bégin, R., et al. (2003). Reduction of hospital utilization in patients with chronic obstructive pulmonary disease: a disease-specific self-management intervention. Archives of Internal Medicine, 163, 585-591.

7. Bourbeau, J., Maltais, F., Rouleau, M., \& Guímont, C. (2004). French-Canadian version of the Chronic Respiratory and St George's Respiratory questionnaires: an assessment of their psychometric properties in patients with chronic obstructive pulmonary disease. Canadian Respiratory Journal: Journal of the Canadian Thoracic Society, 11(7), 480-486.

8. Bourbeau, J., Nault, D., Sedeno, B., Lebel M., Drouin, I., Joubert, A. et al. (2009). Living well with COPD. A plan of action for life. Retrieved from http://livingwellwithcopd. com

9. Brooks, D., Sottana, R., Bell, B., Hanna, M., Laframboise, L., Selvanayagarajah, S., et al. (2007). Characterization of pulmonary rehabilitation programs in Canada in 2005. Canadian Respiratory Journal: Journal of the Canadian Thoracic Society, 14(2), 87-92.

10. Celli, B. R., Cote, C. G., Marin, J. M., Casanova, C., Montes de Oca, M., Mendez, R. A., et al. (2004). The bodymass index, airflow obstruction, dyspnea, and exercise capacity index in chronic obstructive pulmonary disease. The New England Journal of Medicine, 350, 1005-1012.

11. Duffy, J. R., Werven, G. W., \& Aronson, A. E. (1997). Telemedicine and the diagnosis of speech and language disorders. Mayo Clinic Proceedings. Mayo Clinic, 72, 1116-1122.

12. Ferguson, G. T., \& Cherniack, R. M. (1993). Management of chronic obstructive pulmonary disease. The New England Journal of Medicine, 328, 1017-1022.

13. Gosker, H., Wouters, E., van der Vusse, G., \& Schols, A. (2000). Skeletal muscle dysfunction in chronic obstructive pulmonary disease and chronic heart failure: underlying mechanisms and therapy perspectives. American Society for Clinical Nutrition, 71, 1033-1047.

14. Halstead, L. S., Dang, T., Elrod, M., Convit, R. J., Rosen, M. J., \& Woods, S. (2003). Teleassessment compared with live assessment of pressure ulcers in a wound clinic: a pilot study. Advances in Skin \& Wound Care, 16(2), 9196.
15. Hamel, M., Fontaine, R., \& Boissy, P. (2008). In-home telerehabilitation for geriatric patients. IEEE Engineering in Medicine and Biology Magazine, 27(4), 29-37.

16. Hill, A. J., Theodoros, D. G., Russell, T. G., Cahill, L. M., Ward, E. C., \& Clark, K. M. (2006). An Internet-based telerehabilitation system for the assessment of motor speech disorders: a pilot study. American Journal of Speech-Language Pathology, 15(1), 45-56.

17. Lacasse, Y., Brosseau, L., Milne, S., Martin, S., Wong, E., Guyatt, G. H., et al. (2002). Pulmonary rehabilitation for chronic obstructive pulmonary disease. Cochrane Database of Systematic Reviews, 3, CD003793.

18. Lacasse, Y., Martin, S., Lasserson, T. J., \& Goldstein, R. S. (2007). Meta-analysis of respiratory rehabilitation in chronic obstructive pulmonary disease. A Cochrane systematic review. Europa Medicophysica, 43(4), 475485.

19. Lacasse, Y., Wong, E., Guyatt, G. H., King, D., Cook, D. J., \& Goldstein, R. S. (1996). Meta-analysis of respiratory rehabilitation in chronic obstructive pulmonary disease. Lancet, 348, 1115-1119.

20. Lemaire, E. D., Boudrias, Y., \& Greene, G. (2001). Lowbandwidth, Internet-based videoconferencing for physical rehabilitation consultations. $J$ ournal of Telemedicine and Telecare, 7(2), 82-89.

21. Maltais, F., Bourbeau, J., Shapiro, S., Lacasse, Y., Perrault, H., Baltzan, M., et al. (2008). Effects of homebased pulmonary rehabilitation in patients with chronic obstructive pulmonary disease: a randomized trial. Annals of Internal Medicine, 149(12), 869-878.

22. O'Donnell, D., Hernandez, P., Aaron, S., Bourbeau, J., Marciniuk, D., Hodder, R., et al. (2003). Canadian Thoracic Society COPD guidelines: summary of highlights for family doctors. Canadian Respiratory Journal: Journal of the Canadian Thoracic Society, 10(6), 316-319.

23. Ohinmaa, A., Vuolio, S., Haukipuro, K., \& Winblad, I. (2002). A cost-minimization analysis of orthopaedic consultations using videoconferencing in comparison with conventional consulting. Journal of Telemedicine and Telecare, 8(5), 283-289.

24. Pauwels, R., Buist, A., Calverley, P., Jenkins, C., Hurd, S., \& GOLD Scientific Committee. (2001). Global strategy for the diagnosis, management, and prevention of chronic obstructive pulmonary disease. NHLBI/WHO Global initiative for Chronic Obstructive Lung Disease (GOLD) workshop summary. American Journal of Respiratory and Critical Care Medicine, 163(5), 1256-1276.

25. Pepin, V., Saey, D., Laviolette, L., \& Maltais, F. (2007). Exercise capacity in chronic obstructive pulmonary disease: mechanisms of limitation. COPD, 4(3), 195-204.

26. Puhan, M. A., Scharplatz, M., Troosters, T., \& Steurer, J. (2005). Respiratory rehabilitation after acute exacerbation of COPD may reduce risk for readmission and mortality -a systematic review. Respiratory Research, 6(1), 54.

27. Rasekaba, T., Lee, A. L., Naughton, M. T., Williams, T. J., \& Holland, A. E. (2009). The six-minute walk test: a useful metric for the cardiopulmonary patient. Internal Medicine Journal, 39(8), 495-501. 
28. Rejbi, I. B., Trabelsi, Y., Chouchene, A., Ben Turkia, W., Ben Saad, H., Zbidi, A., et al. (2010). Changes in six-minute walking distance during pulmonary rehabilitation in patients with COPD and in healthy subjects. International Journal of Chronic Obstructructive Pulmonary Disease, 5, 209-215.

29. Ricker, J. H., Rosenthal, M., Garay, E., DeLuca, J., Germain, A., Abraham-Fuchs, K., et al. (2002). Telerehabilitation needs: a survey of persons with acquired brain injury. The Journal of Head Trauma Rehabilitation, 17(3), 242-250.

30. Ries, A. L., Kaplan, R. M., Limberg, T. M., \& Prewitt, L. M. (1995). Effects of pulmonary rehabilitation on physiologic and psychosocial outcomes in patients with chronic obstructive pulmonary disease. Annals of Internal Medicine, 122(11), 823-832.

31. Rintala, D. H., Krouskop, T. A., Wright, J. V., Garber, S. L., Frnka, J., Henson, H. K., et al. (2004). Telerehabilitation for veterans with a lower-limb amputation or ulcer: Technical acceptability of data. Journal of Rehabilitation Research Development, 41(3B), 481-490.

32. Savard, L., Borstad, A., Tkachuck, J., Lauderdale, D., \& Conroy, B. (2003). Telerehabilitation consultations for clients with neurologic diagnoses: cases from rural Minnesota and American Samoa. NeuroRehabilitation, 18(2), 93-102.

33. Spruit, M. A., Gosselink, R., Troosters, T., Kasran, A., Gayan-Ramirez, G., Bogaerts, P., et al. (2003). Muscle force during an acute exacerbation in hospitalised patients with COPD and its relationship with CXCL8 and IGF-I. Thorax, 58(9), 752-756.

34. Theodoros, D., Russell, T. G., Hill, A., Cahill, L., \& Clark, K. (2003). Assessment of motor speech disorders online: a pilot study. Journal of Telemedicine and Telecare, 9 Suppl 2, S66-68.

35. Tousignant, M., Boissy, P., Corriveau, H., \& Moffet, H. (2006). In home telerehabilitation for older adults after discharge from an acute hospital or rehabilitation unit: $A$ proof-of-concept study and costs estimation. Disability and Rehabilitation. Assistive Technology, 1(4), 209-216.

36. Tousignant, M., Moffet, H., Boissy, P., Corriveau, H., Cabana, F., \& Marquis, F. (2011). A randomized controlled trial of home telerehabilitation for post-knee arthroplasty. Journal of Telemedicine and Telecare, 17(4), 195-198

37. Vesmarovich, S., Walker, T., Hauber, R. P., Temkin, A., \& Burns, R. (1999). Use of telerehabilitation to manage pressure ulcers in persons with spinal cord injuries. Advances in Wound Care: the Journal for Prevention and Healing, 12(5), 264-269.

\section{ACKNOWLEDGEMENTS}

This research was supported in part by a grant received from the Research Centre on Aging. We would like to thank the study participants. 
